\title{
Chapter 3 \\ Education 2.0: A Vision for Educational Transformation in Egypt
}

\author{
Nariman Moustafa (1), Ebtehal Elghamrawy (D), Katherine King (D), \\ and Yu (Claire) Hao (iD)
}

\begin{abstract}
This chapter presents a comprehensive description and analysis of Egypt's Education 2.0 (EDU. 2.0) reform plan for grades K-2. The reform's five key components are described including the new multidisciplinary curriculum, technology integration, school management Continuous Professional Development (CPD), access and infrastructure, and reformed assessment. We analyze this reform from five perspectives and conclude that a cultural shift, high-quality CPD, and a robust accountability system are imperative to sustainable educational reform in Egypt. This cannot be achieved without a shared vision and engagement between teachers, parents, and Egypt's Education Ministry.
\end{abstract}

\subsection{Introduction}

In 2018, Egypt's Ministry of Education and Technical Education (MoETE) launched an ambitious series of reforms to align with the country's newly developed 2030 Strategic Vision for social and economic change, with a devoted 7th pillar for education and training. The educational reforms aspire to bring large-scale transformation to the country's education system, which has consistently faced persistent strains related to a rapidly increasing student population, deteriorating teaching quality, rigid curriculum, inequality, uncertain political will for change and lack of resources.

In collaboration with Education 2.0 Research and Documentation Project (RDP)

N. Moustafa $(\varangle)$

Graduate of the Masters of Education, Harvard Graduate School of Education, 46 Rabaa

Holdings, El-Nozha Street, Heliopolis, Cairo, Egypt

E. Elghamrawy

Graduate of the Masters of Education, Third Settlement, Harvard Graduate School of Education,

C*30 Stone Park Compound, New Cairo, Cairo, Egypt

K. King

Northeastern University, 25 Shattuck St, Boston, MA 02115, USA

Y. Hao

University of Oxford, Room 9, 38-40 Woodstock Road, Oxford OX2 6HT, UK

(C) The Author(s) 2022

F. M. Reimers et al. (eds.), Education to Build Back Better,

https://doi.org/10.1007/978-3-030-93951-9_3 
Known as Education 2.0 (EDU 2.0), the reforms seek to modernize the country's education system and improve the quality of education for K-12 schooling. The reform's strategic objectives include increasing access to pre-primary education, improving the quality of the K-12 education system in line with international standards, and advancing Egypt's ranking internationally. EDU 2.0 is planned to be implemented in phases between 2018 and 2030. Constrained with limited resources and awaiting the gradual increase in fiscal budget pledged in the 2014 constitution (Nassar, 2019), the MoETE's strategy is to implement this reform gradually to fully transform the education system in grades K-12 by 2030 (Worldbank, 2018). Early grades are to be reformed one year at a time starting in 2018 from pre-primary grades (plan known as EDU 2.0). However, there are simultaneously some selective reforms in higher grades (plan known as EDU 1.0). The objective of EDU 2.0 strategy in its early years of implementation is to transform education in early grades to be "competency-based," focusing on the classroom experience of learners. In parallel, EDU 1.0 also offers some reform actions to students already in the system. By prioritizing and working on key challenges in higher grades such as secondary school assessment, the EDU 1.0 reforms indicate that all students currently within Egypt's education system will receive some extent of the reform proposal, though the focus will be pre-primary and primary grades in the initial phases until EDU 2.0 is fully rolled out to all K-12 (Saavedra, 2019; Worldbank, 2018).

That said, the scope of this paper is on EDU 2.0: in specific K-2. The reform agenda focuses on developing a competency-based, multi-disciplinary, technology-enabled curriculum, in line with the international movement towards fostering 21 st-century skills acquisition. Technology integration, updated teaching pedagogy, and reformed assessments are among the critical reform components. Various stakeholders and international partnerships have contributed to the development and implementation of the EDU 2.0 reforms. The new educational vision aligns with Egypt's 2030 Vision 7 th pillar and the constitutional mandate to recognize education reform as one of Egypt's top priorities.

This chapter will describe and analyze the reforms in Egyptian grades K-2, during their first phase of implementation from 2018 to 2020. The analysis will begin by describing Egypt's unique context, and the preceding reform iterations leading up to the EDU 2.0 reforms. Next, it will describe the primary components of EDU 2.0, to illustrate how this large-scale reform was conceptualized and developed for implementation. It then analyzes the reform using a comprehensive five perspective model on educational change developed by Reimers (2020a, 2020b). Finally, results and implications of the reform are discussed, especially against the larger context of assessing large-scale educational reforms in middle-income countries. As authors, we attempt to provide a critical analysis of the EDU 2.0 reforms from a policy perspective situated in a larger socio-political framework, drawing connections between the intended goals and the known implementation efforts. We argue that a cultural shift, high-quality Continuous Professional Development (CPD), and a robust accountability system are imperative to sustainable educational reform in Egypt, which cannot be achieved without a shared vision between teachers, parents, and MoETE. We contend that to create the desired outcomes, EDU 2.0 must be 
intentionally developed with MoETE collaboration, continuous communication, and engagement with stakeholders.

\subsection{Research implications}

Egypt being a sizable middle-income country with a complex education system, EDU 2.0 can provide valuable insight into the design and implementation of large-scale change. In practice and literature, attention and policy decisions on blended learning have been allocated to higher education than pre-primary and primary school stages (OECD/The World Bank, 2010). Hence, this work can notably contribute to the knowledge surrounding blended learning, public-private partnerships, and digital technology use at the primary level. Additionally, EDU 2.0 may provide insight into teacher development strategies for teaching a multidisciplinary curriculumone which is inclusive of blending learning, as an approach that is relatively new, without much available relevant literature (UIS, 2020). It will also be essential to assess whether Egypt can improve access to early childhood education to its citizens. This is a larger issue, which also requires mitigating issues of inequality (World Bank, 2018). Currently, there are few instances worldwide of a full-fledged multidisciplinary curriculum at the national level. EDU 2.0, if successful, can be impactful in the latter area and may contribute insights to how such a change can take place within a country characterized by a diverse and complex education system, influenced by varied socioeconomic factors.

\subsection{Methodology}

To date, there is no single published EDU 2.0 reform strategy document. As a result, this analysis was built on a comprehensive literature review, and a partnership with the Education 2.0 Research and Documentation Project (RDP) led by Dr. Linda Herrera. The RDP is a collaboration project between the MoETE and the Social Research Center at the American University in Cairo, created to document the reforms and gather data during a time of vast educational change. Working closely with RDP's researchers, the collaboration provided access to unpublished reports and firsthand accounts from teachers, principals, and interview transcripts from relevant stakeholders such as Minister advisors, educational business representatives, and a senior UNICEF Education Officer. RDP provided the authors with a database of 51 published newspaper articles, 74 journal articles and book chapters, 15 statistical reports, 62 press conferences and interviews, and 30 official reports. These documents are a mixture of internal documents, published communications within Egypt, and international reports. The RDP is also working on creating an oral history archive containing qualitative data from various stakeholder interviews. We analyzed 10 interview transcripts previously collected by RDP in addition to conducting four 
firsthand interviews ourselves to complement RDP's archive and offer us a comprehensive insights from all stakeholders. The interviews were semi-structured and sought to elicit perspectives on the design of the reforms, implementation to date, and their application results in relation to achieving Egypt's broader strategic education goals. Our analysis integrated both primary and secondary data sources with Reimers' five perspective framework to assess the intended objectives of the reforms and their implications for vast educational change in Egypt.

\subsection{Context for the reforms}

With an officially announced renewed focus on economic and societal development, Egypt is envisioning a path forward almost a decade after the Arab Spring, the 2011 revolution and years of political power shifts (Mohamed, 2019). Since the Arab Spring of 2011, Egypt has made modest improvements in economic growth and social conditions (World Bank, 2020). However, persistent challenges remain. Poverty, inequality, and unemployment remain barriers to economic advancement, despite aid from international organizations such as USAID, the European Commission, and the International Monetary Fund, designed to support civil society organizations after the uprisings (Elagati, 2013). Unemployment rose to $9.6 \%$ in 2020, with job losses mainly in sectors related to retail and wholesale trade, manufacturing, tourism, transport, and construction (World Bank, 2020). These challenges are compounded by Egypt's rapidly increasing population, which has soared to 102 million in 2020 (Walsh, 2020). With the current trajectory, the population is on track to reach 128 million by 2030 (United Nations, 2020). With the annual population growth around $2 \%$, current economic growth is insufficient to keep pace with this rate of population expansion in Egypt (Mohamed, 2019).

This rapid population growth has placed strains on Egypt's education system, which is the oldest and the largest in the Middle East and North Africa (MENA) region. Supporting over 21 million students in 50,000 schools, the system has undoubtedly been challenged by more significant funding requirements, capacity shortages, and overcrowded classrooms (USAID, 2020a). As a result, the studentto-teacher ratio has increased, teacher capacity has deteriorated, and many teachers cannot provide up to standard learning experiences. Egypt has seen low scores in assessments such as the Trends in International Mathematics and Science Study (TIMSS) and Progress in International Reading Literacy Study (PIRLS). Egypt ranked in the bottom 5\% in PIRLS 2016 and ranked 130 out of 137 in the World Economic Forum's Global Competitiveness Report in 2017-2018 (Olson et al., 2008). These assessments highlight some of the major systemic issues the education system is facing: a lack of sufficient teacher training, strained resources, and insufficient quality assurance. Together, these factors have combined to perpetuate a system where students are not mastering foundational skills at the primary level (El Baradei, 2004). Consequently, under-resourced and overcrowded classrooms diminished the 
education system's ability to provide quality education at an increasing scale (World Bank Statistics, 2021a, 2021b).

Moreover, the standard national curriculum is outdated, and insufficient in delivering quality education. The Egyptian education system has traditionally prioritized rote learning and high-stakes final examinations over active learning and critical thinking (Alan \& Varma, 2020). While the EDU 2.0 reforms attempt to revise some assessment strategies, high-stakes tests still largely determine students' progression throughout the education system and future employment prospects (Mohamed, 2019). The emphasis has been traditionally placed on receiving a credential that could assure a job in the public sector, without regard for students' skills to thrive in the twenty-first century (Saavedra, 2019). The necessity for a restructured education system is more crucial now than ever. With more than 700,000 Egyptians entering the job market every year, Egypt's education system struggles to provide relevant and updated curricula that relates to a modern and changing economy (OECD, 2015).

\subsection{Previous Educational Reforms}

Over the past three decades, several reform strategies, policy changes, and national programs ${ }^{1}$ have attempted to improve Egypt's education system. Except for the Community School Programme, most of these reforms focused on improving access, changing pedagogies, and restructuring teachers' professional development training. There was very little focus on developing students' competencies, improving curriculum development, or creating an assessment of outcomes. Rather, most of these reforms worked in isolation, disregarding a comprehensive view of other critical educational elements or links to the country's larger political and socio-economic conditions. The policies lacked coherence within a comprehensive reform plan as part of the country's strategic objectives.

For example, the 2004 Professional Development focused on improving teachers' pedagogy, without reforming the curriculum or assessing the teacher or the student. Likewise, the 2007-2012 National Education Strategic Plan sought to adopt "a decentralized education system that enhances community participation, good governance, and effective management at the school level as well as at all administrative levels" (Hamdi, 2019). However, the various unrelated and conceptual objectives of the plan limited the Ministry's ability to build and sustain support for the reforms (OECD, 2015). This is still a persistent challenge in education reform in Egypt: there is a lack of coordination from top-down directives to establish and monitor implementation and evaluation or to find grassroots support that sustains the reform.

However, a key outcome of previous reform was an increased number of enrolled students within the education system. Primary grades net enrollment reached $96.9 \%$,

\footnotetext{
${ }^{1}$ Among these are the Community School Programme (1991-2004) the New School Programme (2000, 2007), the Alexandria Pilot Project (2002-2004), the Education Reform Programme (20042009), and National Education Strategic Plan (2007-2012).
} 
and gross enrollment reached 106.4\% in 2019 (UIS, 2020.) Crucially, the reforms successfully expanded access to basic education and achieved improvements in the gender gap parity, which remained substantial until the early 2000s.

Although Egypt has seen several changes because of education reform in the last several years, access to pre-primary enrollment remains one of the lowest in the MENA region at $31 \%$ (UIS, 2020). The gap is primarily attributed to the fact that most accessible schools are concentrated in more affluent regions, and access remains limited to less socioeconomically advantaged communities (PWC, 2018). While Egypt has achieved near universal access to primary education, the quality of education remains a critical challenge. As Tarek Shawki, Minister of Education and Technical Education heading the EDU 2.0 reforms notes, "The classic education system of Egypt had expired" (Saavedra, 2019) The EDU 2.0 reforms hopes to focus on addressing these disparities.

\subsection{EDU 2.0 Reform Description}

EDU 2.0 was introduced by the Egyptian MoETE in August 2017. The reform's primary objectives focus on transitioning the education system away from rote memorization and surface-level learning, and towards an education system that promotes critical thinking, knowledge-based inquiry, and lifelong learning (Saavedra, 2019). The initiative is meant to restructure K-12 education in Egypt drastically, and aligns with Egypt's 2030 Vision for economic, environmental, and social development (Oxford Business Group, 2020). As such, the MoETE plans to have EDU 2.0 fully integrated into the education system by 2030 , with the reforms being gradually implemented in phases beginning at the pre-primary level.

\subsubsection{Key International Partnerships}

The MoETE enlisted the support of several international organizations to finance and collaborate on the reforms. Notably, the World Bank's \$500 million loan “Supporting Egypt Education Reform Project" is designed to align with EDU 2.0 and develop long-term educational engagement in Egypt (World Bank, 2018). The World Bank's project focuses on four primary objectives, which are each integrated with EDU 2.0 strategic goals: (a) increase access to pre-primary education and improve infrastructure, (b) improve the quality of learning by utilizing digital technologies, (c) establish frameworks for continuous professional development for teachers and school leaders, and (d) develop new computer-based assessment and examination systems (World Bank, 2018).

Organizations such as UNICEF and UNESCO were instrumental in collaborating with the MoETE to develop a multidisciplinary curriculum that promotes deeper, competency-based learning. International publishers such as Discovery Education 
and National Geographic have contributed educational materials that cover a range of distinct yet interrelated subjects to expand the existing Egyptian Knowledge Bank (EKB), a first of its kind open source online library of educational content available to all Egyptian citizens (World Bank, 2020).

\subsubsection{Theory of Change}

The MoETE structured the EDU 2.0's components to align with three overarching strategic education objectives: (a) education for all without discrimination, (b) improving the quality of education in line with international standards, (c) bolster Egypt's ranking locally, regionally, and internationally (Ministry of Planning and Economic Development, 2020). Thus, the MoETE's theory of change suggests that if these strategic objectives are met, then Egypt's education system will transform into a culture of learning, accessible to all, and found in the development of competencybased skills. In turn, these reforms are meant to advance Egypt's competitiveness in educational rankings locally, regionally, and nationally. They will contribute to economic and social development in the country, as envisioned with the country's larger national strategy, Egypt's 2030 Vision (Ministry of Planning and Economic Development, 2020).

To achieve such ambitious plans, the reform appears to be centered in five key components: a new multidisciplinary curriculum, technology integration, teachers, and school management. These components are also alongside Continuous Professional Development (CPD), access and infrastructure, and reformed assessment. The development and key elements of each component is discussed below.

\subsubsection{Multidisciplinary Curriculum}

As part of the first implementation phases of EDU 2.0, a new K-2 curriculum was developed under the Ministry's Center of Curriculum and Instructional Materials Development (CCIMD) leadership. This was done in partnership with multilateral organizations including UNICEF and UNESCO, and private trans-national corporations like Discovery Education (DE). Nahdet Misr, a national privately owned business, was also in consultation (UNICEF, 2018). As a result of these collaborations, the General Framework for the General and Technical Education Curricula (GFGTEC) was designed for the primary grades. This framework complemented the competency-based and multidisciplinary curriculum, which the MoETE later produced for primary and pre-primary grades.

The GFGTEC is a 21st-century skills framework based on the UNICEF-MENA Life Skills and Citizenship Education (LSCE) framework. The LSCE is grounded in the principles of UNICEF framework (UNICEF MENA, 2017). It contains (a) a new curriculum design including standards, activities, and outcomes for each grade level, (b) new physical and digital textbooks, (c) teacher guides, (d) open digital learning 
content for each chapter for each grade and subject, and (e) a learning management system on the Egyptian Knowledge Bank and an offline app (Discovery Education, 2019a).

The framework and the curriculum center learning around fourteen skills, which should be acquired by each child in their pre-tertiary education. This includes twelve skills from UNICEF LSCE's framework, and two skills (accountability and productivity) proposed by MoETE to fit the Egyptian context (El-Zayat, 2020).

\subsubsection{Technology Integration}

To contend with issues related to deteriorating learning quality, and to modernize the education system, the MoETE had already begun to make the shift towards blended learning strategies and their integration into the national curriculum by the time the EDU 2.0 reforms were introduced. The Egyptian Knowledge Bank was launched in 2016 and continues to be utilized widely in primary level education (Saavedra, 2019). Now available to 23 million teachers and students, the platform is meant to be easily accessible by laptops and mobile phones anywhere in the country and free of charge (Discovery Education, 2020).

The EKB contains encyclopedias in both English and Arabic, online dictionaries, interactive lessons, and a range of books and scientific articles for all ages and preparatory levels. It also contains three hours of originally produced online video programs broadcast daily on WebEdTV, which are customized to the Egyptian national curriculum (Discovery Education, 2020). Teachers can access teaching materials on the EKB that align with the EDU 2.0 curriculum and are able to integrate lessons from the platform into their teaching plans. There are also tools available within the EKB to help monitor student progress and collect data on student activity (Discovery Education, 2020).

In addition to the EKB, the technology integration within EDU 2.0 also sought to digitize the assessment methodology and expand assessment strategies. New computerized assessments were introduced, with the goal of increasing students' competencies in twenty-first century skills while shifting away from rote test memorization.

\subsubsection{Teacher and School Management Continuous Professional Development}

From a strategic planning and policy perspective, the MoETE seems to recognize the need for CPD programs to build and enhance teachers' ability to deliver the reforms' desired objectives (World Bank, 2018). This is evident where teacher and school management professional development has been identified as key to several initiatives within the EDU 2.0 reforms, especially through redesigning a comprehensive CPD framework (World Bank, 2018). Such a framework ought to include foundational teacher training, induction training, and curriculum-based training. Additional 
assessment of hiring policies, promotion, teacher evaluation, and licensure policies is also needed (World Bank, 2018). Some of these initiatives have been implemented, while others are still under development.

\subsubsection{Teachers First}

The "Teachers First" initiative was co-developed and co-implemented with the private international education organization Imagine Education. The training framework was developed specifically for Egypt and is based on the UNESCO Competency Framework for Teachers (Imagine Education, 2020). It focused on changing attitudes and behaviors. Its four primary pillars included CPD, communities of practice, mentoring, and the use of an online platform for a three-way assessment strategy (self, peer, mentor). These pillars were implemented through training topics such as classroom management, introduction to 21 st-century skills, introduction to digital skills, resourceful/innovative teaching pedagogies, and life-long learning skills (Teachers First, 2020). It was implemented in a cascade format, which proceeds as follows.

First, the school principal recommended three teachers to attend a series of workshops outside of the school. Upon return, they were expected to create a PD unit at their school, in which other teachers were trained on best practices in educational pedagogy. At the same time, the teachers participated in an online community of practice on an online app called "Lengo," which collected awarded credits for selfreported improved professional behavior. They could also receive credits from a mentor or colleague. (Teachers First, 2020).

Teachers First was launched in July 2016, before the official EDU 2.0 reform plan announcement; however, it was discontinued in 2019. The official statement was that "the program did achieve its objective in building the foundation of Egypt's teachers, and now Teachers First goes from impact to sustainability across Egypt" (Teachers First, 2020).

\subsubsection{Discovery Education}

The education company Discovery Education implemented a curriculum training in 2018, designed to help teachers align with teaching an updated and competency-based curriculum. A series of workshops and trainings was complemented by a detailed teacher guide for the new curriculum, online training and resources, and online Community of Practice (CoP) on a new digital teacher platform, called Professional Learning Journey PLJ (Discovery Education, 2018a, 2018d, 2018e).

The Discovery Education model was also implemented in the form of a cascade training, whereby the MoETE worked in collaboration with Discovery Education to organize a Training of Trainers (TOT) for early-grade teachers and supervisors to be master trainers; these trainers then went on to train the remaining early-grade teachers in all 27 governorates. Delivered in a mandatory three days of training per semester, most early grade teachers and primary school principals took the training (Discovery 
Education, 2019a). It was co-developed by CCIMD and Discovery Education and supported by the MoETE budget and USAID as an early grade learning project of $\$ 15$ million (USAID, 2020c). The implementation had three components: (a) supervisors complete training three days a term, (b) regular school visits and follow up from the MoETE trainer supervisors and Discovery Education team (with data collected digitally during visits), and (c) an online PD and CoP using PLJ teacher framework to enable continuous professional development (Discovery Education, 2018a). The implementation is still ongoing.

\subsubsection{Access and Infrastructure}

The access and infrastructure component of the reform is divided between preeducation and primary education. Thus, the World Bank has dedicated \$100 million towards increasing access to pre-primary education, while simultaneously improving the quality of education. The project supports the identification of available spaces in existing schools or community buildings, equipping pre-primary classrooms with furnishings and educational resources, and building and equipping entirely new classrooms (World Bank, 2018). There is a specific focus on reaching underserved communities that have traditionally struggled to gain access to early childhood education.

At the primary level, the access and infrastructure objectives are focused on contending with overcrowding and a lack of resources in Egypt's public schools. The objectives center around repairing existing buildings, while creating plans to scale up the resources available. New education tools are proposed to assist with this endeavor, especially digital technology — which is promoted as a method of modernizing the curriculum, while also leveraging students' ability to complete some tasks at home.

\subsubsection{Reformed Assessment}

With the shift away from rote memorization and high stakes examinations, the EDU 2.0 reforms have highlighted the need for an assessment and examination system which is "[F]air, valid, and reliable" (World Bank, 2018). A new assessment plan accompanies the new curriculum, which favors comprehensive assessments based on a multidisciplinary approach to learning.

Prior to grade 4, examinations have been eliminated entirely and replaced by formative assessments. A student annual report developed by the teacher assesses each child's progress (verbal, written, assigned competencies) on a matrix of four levels, ranging from "above expectation" to "less than expected." This strategy attempts to cultivate internal motivation for learning in the formative years, rather than extrinsic pressure to perform well on exams (MoETE, 2015). 


\subsection{Known Results}

The first phase of the K-2 reforms was planned and launched in a tight timeline from 2017 to 2018, and consequently, several key documents and data sources are missing - each of which would be useful to provide insight into the reform's development and implementation. From our literature review and interviews with key stakeholders, it seems that documents outlining the objectives and implementation strategy for the reforms are neither created, collected, consolidated, nor published yet. A comprehensive strategy plan, work-plan, monitoring and evaluation plan, and communication plan are all missing/unpublished at this stage. Furthermore, baseline assessments on main indicators, progress reports, and quality input measurements are not available, but necessary to measure known results and predict future outcomes. Lastly, evidence of the perception of the reforms, engagement in the implementation, and application of key features are missing among students, teachers, and parents alike. Having these accounts will be useful to continuous quality improvement in the implementation phase. Moreover, these "bottom up" perspectives could be useful in securing buy-in for community engagement and garnering support for education reform.

The sections below are a summative report on key indicators and reported results, covering the period between 2018-2019 and 2019-2020 results are not all published or collected at this time.

\subsubsection{Multidisciplinary Curriculum}

In collaboration with CCIMD, UNICEF, and Discovery Education, the MoETE was successful in completing several key objectives. These include defining new learning objectives for pre-primary through grade 2, developing new learning content using the UNICEF LSCE framework, creating new textbooks and teacher guides using the EDU 2.0 and LSCE framework, and implementing the new curriculum in schools for pre-primary education through grade 2. Discovery Education continues to work closely with the CCIMD to build capacity, review the curriculum framework, and develop the printed and digital content for students and teachers.

\subsubsection{Technology Integration}

Technology integration is integral to the EDU 2.0 reforms, and digital infrastructure has been developed to support this scheme. There are over 2,400 digital content resources for pre-primary through grade 2, and 9,349 digitally equipped schools. Students continue to have access to digital learning platforms such as the EKB, Edmodo, and Discovery Education (Egyptian Ministry of Education Information 
Center, 2019). This is part of wider digital learning expansion, whereby the MoETE established 9,249 computer labs within Egypt's public schools, and approximately 27,500 classrooms were equipped with digital hardware. Considering the size of Egypt's education system, however, this only represents $16 \%$ of the total nation's schools (Oxford Business Group, 2017). Besides, technology alone did not solve the challenges of educational access and quality in classrooms. The uptake of digital technology does not automatically lead to improvement in access or educational outcome, due to challenges such as digital literacy among teachers and students. Despite the significant undertaking of building digital infrastructure, there is widespread need throughout the country to increase internet connectivity, and to deploy a universal learning management system that could support online learning (World Bank, 2018). During the pandemic, school closures led to enforced digital access. Yet, the gap remains for future research to continue collecting data to understand whether and how technology is achieving the goals of EDU 2.0.

\subsubsection{Teacher and School Management Continuous Professional Development}

The reforms have made significant strides in improving CPD initiatives, all supported by USAID, the World Bank, and Discovery Education. A national teacher training framework was achieved for pre-primary-grade 2, and new teachers now receive content training in CPD initiatives for the new curriculum. 96,000 teachers have been trained using a cascade model, where 5,000 teachers receive a master teacher certification and go on to train others in their cities. 1,500 supervisors oversee this process, and report on it using PLJ (Egyptian Ministry of Education Information Center, 2019; Discovery Education, 2019a).

\subsubsection{Access and Infrastructure}

3,331 new schools were constructed, and 1,955 classrooms were refurbished. Particular attention was paid to pre-primary schools and classrooms, and to expanding access to pre-primary education in communities that had limited access. The World Bank is a key collaborator in expanding access and infrastructure and plans for mapping new school and classroom spaces are ongoing (World Bank, 2018). 


\subsubsection{Reformed Assessment}

Summative assessments for pre-primary through grade three were eliminated and replaced with formative assessments aimed to target more competency-based learning (Egyptian Ministry of Education Information Center, 2019). As curriculum training develops, there is continued work to address the alignment between teacher training and new assessment strategies that support a competency-based curriculum rather than high stakes examinations. A missing area is also addressing parents perceptions and mindsets around assessments after decades of being accustomed to the need for high-stakes examinations and grades as their only proof for their children's education.

\subsubsection{Future Directions}

It appears that MoETE has been successful in achieving some of the desired outputs, but it is unclear, however, how these resources are equitably distributed between various groups. Furthermore, more information is needed to assess how these outputs are translated into outcomes or further yet connected to the impact articulated in the announced Theory of Change. Many of the available indicators do not measure implementation quality, which is important to establish in assessing the ongoing implementation of the reforms.

\subsection{Analysis}

Reimers' (2020a, 2020b) five perspective framework allows us to analyze how this national-level reform was designed and implemented to achieve the stated goalslargely, improving educational access and quality. The framework includes cultural, psychological, professional, political, and institutional lenses, which operate together to provide a comprehensive understanding of the complexity and interconnectedness of the reform components within its larger socio-political context.

\subsubsection{Cultural Perspective}

The cultural perspective of the reforms highlights the relationship between the education system and the larger societal context. It reveals the impact of education and its goals on societal expectations, as both the society and the education system change over time (Reimers, 2020a, 2020b). The EDU 2.0 reforms mark a drastic shift in the 
culture of Egyptian education, in which the traditional methods of rote memorization and high stakes examinations are exchanged for a multidisciplinary approach to teaching and learning 21st-century skills via technology integration. Making significant changes within a complex education system such as Egypt's is challenging and is limited by the traditional top-down approach that the MoETE has traditionally relied upon. The Minister acknowledged that the biggest needed change, however, is one in citizens' mindsets-stating, "The root problem is cultural, in one aspect" (Saavedra, 2019).

For large-scale change to be sustainable, the MoETE recognizes the need to engage the participants in the education system and to maintain communication as the reforms develop (El-Zayat, 2020). There have been efforts by the MoETE to communicate directly with parents via social media and online messaging platforms, but a comprehensive communication plan outlining the shift in pedagogy and its impacts on students and their families has not yet been developed (El-Zayat, 2020). Thus, for a successful cultural shift surrounding the goals and value of education to take place, it is imperative to open channels of communication and clearly define the objectives of the reforms, such that all citizens can buy-in and play a role in implementing and sustaining change.

\subsubsection{Curricular Considerations}

A cultural analysis of EDU 2.0 also lends itself to an examination of the newly introduced curriculum's larger impact. While the new curriculum is mapped to international frameworks and standards, further research is needed to assess whether they are integrating Egypt's local and diverse epistemologies. To be clear, this focus is not about incorporating diversity lessons in the curriculum or their outcomes. Rather, it is about integrating a local epistemology and ontology; of what is worth knowing, how it should be known, and what is to be true. This stands in contrast to an entirely Western-centric lens, upon which international organizations and corporations (EDU 2.0 new curriculum partners) entirely rely to customarily develop educational content. From our research, it does not appear that the partnerships-be they consultative or as part of the design process - took this point into account, which we recognize as a gap towards achieving a stated vision. Egypt's specific context is an important point to consider in educational reform. The interplay between what the society values and how the education system responds to these values helps define how education will be up-taken by and understood in the society (Reimers, 2020a, 2020b).

\subsubsection{Political Perspective}

The connection between the education system and the larger society with its different interest groups and the power each holds is a salient consideration in the political perspective of analysis. This perspective recognizes that there are variations in the 
interests of particular groups involved in educational reform, and the dynamics of these groups may affect how education is politicized both locally and nationally (Reimers, 2020a, 2020b). Integrated into Egypt's national economic and social development strategy and the 2014 constitution, education was identified as one of the country's top priorities for the next decade (Nassar, 2019). As Article 19 of the Egyptian Constitution (2014) states, "The state commits to uphold its aims in education curricula and methods, and to provide education in accordance with global quality criteria" (Nassar, 2019). Article 19 also requires that government spending on the education sector be "[E]qual at least 4\% of GDP" (Oxford Business Group, 2020). While this expenditure fell short of that target in recent years, it has gradually risen while not yet reaching the 4\% (Oxford Business Group, 2020). Through official documents, education is designated as a top priority in Egypt and is currently supported by the Country President. However, different sources vary in their analysis of whether there is a serious political will behind a massive education transformation like this. Some sources see the support is evident through the funding and the space to create such a change, and others see it unclear given the alarmingly rising inequity in the country (Hamed, 2019). Additionally, there are competing interests for budget allocations, both within the education sector and external to it (Nassar, 2019). Consequently, there are questions as to whether the government has the means to finance such ambitious reform plans (Nassar, 2019).

\subsubsection{Social Engagement}

The EDU 2.0 reforms require the alignment of key stakeholders and the development of shared goals within a complex education system. Considering the various ideas, understandings, and goals of these actors is essential in developing a reform strategy. The interests of parents, for example, may be vastly different than those of teachers, or of large bureaucracies. The misalignment of interests can have negative consequences on the success of the reform strategy. For example, Egyptian teachers have consistently advocated for increased salaries to contend with the challenges presented by an already strained education system and have not yet received compensation in line with international recommendations (World Bank, 2018). If the call for increased salaries is consistently ignored, the government risks losing its current teachers, and may be unable to recruit new teachers in the future-which will affect the reform's ability to be sustainable over time.

A key advantage of educational change is the social transformation that often comes with it, and the opportunity to reduce equity gaps while advancing societal involvement. In many ways, education policy reflects the social contract between a government and its citizenry. This is particularly important for a country like Egypt, which has seen a significant decline in its social justice and human rights indiceswhile growth in its economic sector mostly benefits the larger-income populace (World Bank Education Statistics, 2021a, b). In a country with alarming inequities like Egypt, social justice and reducing equity gaps need to be a central commitment for reform (Zaki Ewiss et al., 2019). 


\subsubsection{Psychological Perspective}

An analysis of EDU 2.0 through the psychological perspective highlights how theories of learning relate to teaching pedagogy. It can provide insights on what students should be learning, and the best practices for how they should be learning it (Reimers, 2020a, 2020b). Evidence-based learning theory is particularly salient for the EDU 2.0 reforms, which entail the re-evaluation of assessments, educational content, and teacher training programs. Egypt's CCIMD collaborated closely with several key organizations to develop learning content and professional development initiatives that are aligned with international frameworks and best practices in education.

Currently, UNICEF's Life Skills and Citizenship Education (LSCE) framework, the DeSeCo 4-pillar learning dimension and skill outcomes, and UNESCO's teacher training framework are all mapped and benchmarked to international standards which are mostly inspired by the International Baccalaureate (IB) system (El-Zayat, 2020). As a result, the curriculum has a well-defined framework that states its standards, goals, detailed units and themes, projects, and outcomes. The curriculum is also aligned with the Global Education Movement's goals and identified best practices, with a focus on citizenship and sustainable development education (UNICEF, 2018). This alignment with international education standards resulted in the formation of a new curriculum that follows the widely known Western-centric psychology-based education science perspective on how people learn (El-Zayat, 2020). On a policy level, the clearly defined objectives and integration of CPD have allowed the CCIMD to develop learning goals for each grade, and teacher training initiatives that target teachers' ability to deliver the curriculum's objectives.

An overarching objective for curriculum reform with EDU 2.0 was to develop cohesive frameworks to improve the development of 21 st-century skills. At each stage of primary education, students should be able to demonstrate skills that improve cognitive, socio-emotional, and behavioral understanding and ability (World Bank, 2018). Notably, Egypt's adoption of the UNICEF's LSCE framework was essential in developing an underlying framework for curriculum and instruction. Egypt was the first Arab country to use UNICEF's framework and operationalize it at the national scale, rather than as a separate curriculum unit or extracurricular activity (El-Zayat, 2020). Perhaps as a result, UNICEF's framework is now used in 14 other Arab countries.

\subsubsection{Continuous Professional Development in the Psychological Perspective}

In addition to defining the competencies that students should be learning, the psychological perspective also encompasses how teachers can be supported in helping students develop these competencies (Reimers, 2020a, 2020b). The implementation of the new EDU 2.0 curriculum under a tight timeline and through a top-down 
approach is challenging, particularly for teachers who are managing new concepts and pedagogies which require behavioral change.

The standard three days of professional training per term is not sufficient for teachers to be supported in teaching effectively. Rather, additional CPD and onground coaching is required for teachers to truly practice teaching the competencies they are trying to develop in their students. As the goal of education in Egypt shifts towards capacity building, teachers will have to help students understand that they "[D]o not need to memorize and achieve certain grades" for high academic achievement (Egypt Today, 2018). Instead, teachers will have to develop teaching strategies that support the competency-based approach that the new curriculum defines (UNICEF, 2018). In terms of competency-based assessments, consideration of how to assess students understand new ideas, solve problems, and retain information will be essential to align the objectives of the curriculum with effective teaching strategies, as well as in conveying to students that academic achievement will be more broadly defined and assessed. As the new curriculum is developed, the psychological perspective will require that the "[O]perational definitions and measurements of the desired competencies" continue to be monitored and assessed (Reimers, 2020a, 2020b, p.12).

\subsubsection{Institutional Perspective}

The EDU 2.0 reforms were developed with the support of both international and local partners. These partnerships were necessary to establish a unified Egyptiancentered vision of educational reform, with a comprehensive view of the infrastructure needed to support it. The institutional perspective highlights how these partners collaborated and aligned with one another to create a system of support, which made implementation of the EDU 2.0 reforms possible (Reimers, 2020a, 2020b).

To build institutional support, the MoETE obtained financial resources for projects related to the EDU 2.0 reforms, such as a \$500 million loan from the World Bank. It also expanded its digital technology infrastructure by aligning the EKB with the new curriculum and created a new partnership with a private internet company to offer subsidized internet access to students. Furthermore, through its partnership with USAID's Teach for Tomorrow Project, the MOETE aims to develop the Teacher CPD system into a teacher career ladder, with professional licensing and incentivization mechanisms between 2020 and 2024 (USAID, 2020b).

In terms of building the capacity of its bureaucratic bodies, the MoETE worked closely with the CCIMD, its national curriculum development body, through training and discussions with partners like Discovery Education and UNICEF (El-Zayat, 2020). Additionally, the World Bank project proposal includes a restructuring of the National Center for Examinations and Educational Evaluations (NCEEE), with the goal of enhancing its capacity as an assessment center, especially in terms of administering computer-based assessments. (World Bank, 2018). 


\subsubsection{Monitoring and Evaluation}

The highly centralized nature of the Egyptian governance system, and its ability to accurately monitor impact and outcomes, remains challenging. Data collection and monitoring for such wide-scale change across so many levels of stakeholders presents issues the MoETE has not yet fully contended with. For example, schools received no communication regarding the roll-out of new textbooks in September 2018 until August 2018 (Sharouda, 2020). Presently, there is no work plan in place to define the reform's objectives or to delineate the specific tasks for all partners (Sharouda, 2020). Teachers, supervisors, and parents constantly struggle to find the information they need, often resorting to Facebook and WhatsApp groups to communicate and inform one another (Sharouda, 2020). EDU 2.0 is an ambitious reform, requiring significant capacity building and guidance on implementation. As such, the stakeholders involved require clear objectives and communication to prioritize tasks and develop a coherent alignment of the reform's goals and implementation strategy.

Another issue is a lack of a clear incentive structure, as well as a lack of accountability mechanisms for school staff to create change. This is particularly salient considering the Ministry's announced inability to increase budgets for teacher salaries, as well as its lack of capacity for recruiting teachers as permanent employees (Hamdi, 2019). The system is also currently missing a comprehensive assessment process, to deliver feedback on the performance of schools as learning organizations. Building on what exists at the school level, involving parents and teachers in genuine communal participation, and considering more autonomous school governance models are all options that can be considered as the reform moves forward (OECD, 2011; Sharouda, 2020).

\subsubsection{Professional Perspective}

From a professional perspective, the reforms can be analyzed according to their ability to be guided by impactful instruction and expert knowledge (Reimers, 2020a, 2020b). This perspective highlights the ability of teachers to operate successfully, and CPD generally. In the Egyptian context, it is essential to analyze not only teachers' "[P]rofessional mindsets and skills," but also the "necessary autonomy and voice" for the new and unexpected challenges of the reform (Reimers, 2020a, 2020b, p.16).

Reviewing the Teachers First program, it seems inclusive of key CPD components. It is favorable to work on teachers' behavior and mindsets ahead of launching a new curriculum. Yet, the program was discontinued on the premise that it was successful and could thus be moved into a sustainability stage (Teachers First, 2020). Arguably, this perspective is unjustified, especially since behavioral change usually takes time, intention, and multiple steps (Harvard Medical School, 2012). 
According to Marey et al. (2020), for example, supervisors had previously conducted school visits and evaluated teachers' performance based on a designated rubric that measured learning outcomes. Now, using the Discovery Education teachers" framework, supervisors assess teachers on the "GROW" model, which encompasses effective listening, positive feedback, and assisting teachers' professional development for mentoring other teachers. The supervisor role is designed to move into a mentorship and support role. Arguably, it is risky to bet complex objectives on six days of training a year, delivered in a cascade model: this raises questions on priorities, efficiency, and strategy.

These challenges are not presented to discount tangible achievements the reforms have made so far. The adoption of a new curriculum, the creation of new educational content, and the development of high-quality teacher training materials is no easy feat, especially considering the timeframe in which they were delivered. Challenges remain in the implementation of the reform goals. According to the 6,000 school visit reports produced by Discovery Education, there are five common challenges identified in schools - these include teachers' guide utilization, teaching instructions, community engagement, and training gaps.

\subsubsection{Teacher Engagement}

These remaining challenges, among others, hinder the system's ability to achieve the identified reform goals and objectives. For example, even though teachers' guides and the PLJ platform offer effective information and teaching strategies, some teachers lack understanding of the development vision, have the wrong conceptual understanding, or persistently prioritize only knowledge-based objectives (Discovery Education, 2018b). At the administrative level, the implementation is constrained by a deficiency in the total number of teachers (especially at pre-primary levels), and the difficulty of dividing the class into groups due to students' density (Discovery Education, 2018b). It is positive that MoETE and its CPD partners delve into addressing these challenges. In this respect, the reform highlights the complexity of teachers' behavioral change as a mechanism of implementing new reform.

Contending with a top-down approach, it is critical to understand teachers' voices throughout the reform at the classroom level. To develop a culture of excellence among teachers and provide motivation for teachers to follow EDU 2.0 PD objectives framework, it is essential to consider teachers' contributions to the educational system, and to identify ways in which their feedback can be elicited and integrated into sustainable change (Hamdi, 2019). Additional research is needed in understanding the impact of Egyptian teachers' agency during the reform implementation in the current central structure. 


\subsection{Reform Status in the Time of COVID-19}

COVID-19 accelerated the progress of the MoETE Education 2.0 reform plan, especially regarding utilizing digital infrastructure and technology integration. When the MoETE ordered schools to close on 15th of March 2020, there was existing infrastructure to enable a transition to online learning (El-Zayat, 2020). The Egyptian Knowledge Bank (EKB) already contained a robust database of educational material that the Ministry could utilize to develop a focused strategy for teaching and learning in the wake of the pandemic. This was extended to all grades starting from pre-primary grades, where digital content was matched per unit for each subject (El-Zayat, 2020). Moreover, the MoETE partnered with other technology companies such as Edmodo to deliver interactive sessions between teachers and students, where more than $85 \%$ of teachers were registered by May 2020 (El-Zayat, 2020). This would have been considered an unimaginable figure pre-pandemic and indicates that stakeholder engagement significantly increased because of necessity. That said, it is essential to highlight that there was apparent institutional unpreparedness with the rapid implementation in March 2020. The implementation did not have proper institutional support, as again, it was managed and run top-down. Teachers weren't equipped to teach or interact online, students and families were unfamiliar with online learning, and there is a national shortage of access to proper digital infrastructure (ElZayat, 2020). This illuminates that critical next steps must yet be taken to fill the gaps that remain in implementing policy to match conceptual plans with adequate grassroots support. In this sense, the pandemic will ultimately become a valuable case study for the MoETE as it moves forward with refining and implementing its EDU 2.0 strategy on a larger scale.

\subsection{Conclusion}

Through a description of the EDU 2.0 reform and a critical analysis of what is known about it and its results so far, this chapter draws parallels between the objectives of educational reform and the factors which impact its implementation. Egypt's unique context is considered to highlight the specific conditions which have given rise to the reform, and which may in turn be influenced by it. Information garnered from international reports, an oral history archive, and national media sources allowed us to discuss the reform process through multiple lenses and perspectives, and to draw connections between the various stakeholders involved. Our analysis conveys that the reforms have a bearing on many aspects of Egyptian life at both micro and macro levels, as schools contend with new teaching and learning strategies, and while the MoETE attempts to fundamentally shift how education is conceptualized throughout the country.

While the vision to integrate technology within a multidisciplinary curriculum in Egypt is ambitious, COVID-19 has demonstrated that it may be possible with more 
infrastructure, attention to equity and access disparities and the need for grassroots support or buy-in. Moving forward, successful implementation of the reforms will depend on the system's ability to create sustainable change. Monitoring and evaluation systems are needed, as is a cultural shift to engage the community and build support, particularly among teachers and parents. As EDU 2.0 continues to be implemented over the next decade, the reforms will undoubtedly be influential in defining educational priorities and shaping the future of Egypt's education system for generations to come. On the international level, Egypt's reform implementation is poised to contribute to education reform literature in low-middle income countries. With its specific focus on kindergarten and primary students, Education 2.0 also can advance the knowledge base in areas related to curriculum reform impact and technology integration, especially in terms of teaching and learning for early grade levels.

\section{References}

Alan, S., \& Varma, P. (2020). Strengthening the Egyptian education system: A recap from the global evidence for Egypt spotlight seminar on education. Available via The Abdul Latif Jameel Poverty Action Lab (J-PAL). https://www.povertyactionlab.org/blog/2-28-20/strengthening-egy ptian-education-system-recap-global-evidence-egypt-spotlight-seminar. Accessed 22 Sept 2020.

Boston College TIMSS \& PIRLS. (2015). International reports. Available via Boston College Lynch School of Education. https://timssandpirls.bc.edu/. Accessed 15 Nov 2020.

Discovery Education. (2018a). Curriculum professional development report, Education 2.0. Unpublished report.

Discovery Education. (2018b). Supervisors report, Education 2.0. Unpublished report.

Discovery Education. (2018c). Schedule and attendance for 2018, Education 2.0. Unpublished report.

Discovery Education. (2018d). Education 2.0 supervisors' primary PD overview, Education 2.0. Unpublished report.

Discovery Education. (2018e). Education 2.0 teachers' primary PD overview, Education 2.0. Unpublished report

Discovery Education. (2019a). Egypt progress report, February 2019. Unpublished report.

Discovery Education. (2019b). Evaluation methods and tools for education 2.0: Kg 1, KG 2, P1. Unpublished report.

El Baradei, M., \& El Baradei, L. (2004). Needs assessment of the education sector in Egypt. Center for Development Research (ZEF), University of Bonn.

Egypt Today. (2018). Exclusive interview: Education minister details new system. Available via Egypt Today. https://www.egypttoday.com/Article/1/61368/Exclusive-Interview-Education-min ister-details-new-system. Accessed 22 Oct 2020.

Egyptian Ministry of Education Information Center. (2019). Statistical yearbook 2019-2020. http:// emis.gov.eg/Site\%20Content/book/019-020/pdf/1.pdf. Accessed 22 Sept 2020.

Egyptian Knowledge Bank (EKB). (2020). About the EKB. https://www.ekb.eg/about-us. Accessed 1 Nov 2020.

Elagati, M. (2013). Foreign funding in Egypt after the revolution. Available via FRIDE, AFA, and Hivos. https://www.files.ethz.ch/isn/162759/WP_EGYPT.pdf. Accessed 3 Nov 2020.

El-Zayat, N. (2020). Egypt: K-12 Egyptian knowledge bank study portal and new form of assessment. Available via World Bank https://documents1.worldbank.org/curated/en/191341599 145436193/pdf/Egypt-K-12-Egyptian-Knowledge-Bank-Study-Portal-and-New-Form-of-Ass essment.pdf. Accessed 13 Nov 2020. 
Ginsburg, M., \& Megahed, N. (2008). Global discourses \& educational reform in Egypt: The case of active-learning pedagogies. Mediterranean Journal of Educational Studies, 13(2), 91-115.

Hamdi, A. (2019). Assessment of Egypt's new education reform system. Available via Egyptian Institute for Studies. https://en.eipss-eg.org/assessment-of-egypts-new-education-reform-sys tem/. Accessed 2 Dec 2020.

Harvard Medical School. (2012). Why behavior change is hard and why you should keep trying. Available via Harvard Heath Publishing. https://www.health.harvard.edu/mind-and-mood/whybehavior-change-is-hard-and-why-you-should-keep-trying. Accessed 2 Dec 2020.

Imagine Education. (2020). Teachers first for Egypt. https://www.imagine.education/casestudies/ teachers-first-egypt. Accessed 20 Feb 2021.

Marey, R., Hesham, G., Magdd, A., \& Toprak, M. (2020). Re-conceptualizing teacher evaluation and supervision in the light of educational reforms in Egypt. Social Sciences \& Humanities Open, 2(1).

Ministry of Planning and Economic Development. (2020). Egypt's vision 2030: Sustainable development goals. Available via Egyptian Ministry of Planning and Economic Development. https://mped.gov.eg/EgyptVision?lang=en\#: :text=Egypt\%20Vision\%202030\%20focu ses\%20on,life\%2C\%20in\%20conjunction\%20with\%20high\%2C. Accessed 3 Mar 2020.

MOETE. (2015). Strategic plan for pre-university education. Available via UNESCO. http://www. unesco.org/education/edurights/media/docs/c33b72f4c03c58424c5ff258cc6aeae0eb58de4.pdf. Accessed 12 Dec 2020.

Mohamed, R. (2019). Education in Egypt. Available via WENR. https://wenr.wes.org/2019/02/edu cation-in-egypt-2. Accessed 21 Oct 2020.

Nassar, S. (2019). The right to education in Egypt. Available via Studies in Human Rights. https://hri ghtsstudies.sis.gov.eg/studies-reports/studies/the-right-to-education-in-egypt/. Accessed $21 \mathrm{Sept}$ 2020.

OECD. (2015). Schools for skills: A new learning agenda for Egypt. Available via Organisation for Economic Co-Operation and Development. https://www.oecd.org/countries/egypt/Schoolsfor-skills-a-new-learning-agenda-for-Egypt.pdf. Accessed 26 Sept 2020.

OECD. (2011). Lessons from PISA for the United States, strong performers and successful reformers in education: Available via OECD Publishing. https://doi.org/10.1787/978926409666 0 -en. Accessed 2 Sept 2020.

OECD/The World Bank. (2010). Reviews of national policies for education: Higher education in Egypt 2010. Available via Reviews of National Policies for Education, OECD Publishing. https:// doi.org/10.1787/9789264084346-en.Accessed5Nov2020

Olson, F., Martin, O., \& Mullis, S. (2008). TIMSS \& PIRLS international study center, Boston College.

Oxford Business Group. (2017). How will Egypt reform its education system? Available via Oxford Business Group. https://oxfordbusinessgroup.com/overview/forging-ahead-new-reforms-invest ment-and-initiatives-are-aimed-fixing-ongoing-problems-and. Accessed 7 Nov 2020.

Oxford Business Group. (2020). What infrastructure will aid Egypt's digital transformation? Available via Oxford Business Group. https://oxfordbusinessgroup.com/overview/mobile-connectionnew-legislation-and-continuing-investment-communications-infrastructure-set. Accessed 7 Nov 2020.

PWC. (2018). Education sector in Egypt: Understanding Middle East education. Available via PWC. https://www.pwc.com/m1/en/industries/education/education-country-profile-egypt.html. Accessed 15 Sept 2020.

Reimers, F. (2020a). Audacious education purposes. Springer Open.

Reimers, F. (2020b). Educating students to improve the world. Springer Open.

Saavedra, J. (2019). Shaking up Egypt's public education system. Available via World Bank. https:// blogs.worldbank.org/education/shaking-egypts-public-education-system. Accessed 2 Sept 2020.

Sharouda. (2020). EDU 2.0 Research and Documentation Project (RDP) Oral History Collection (2020).Transcript with Manar Ahmed Sharouda of UNICEF. Edited by Linda Herrera, Cairo 
Teachers First. (2020). Teachers first: An initiative of the MOETE. https://teachersfirstegypt. com/ar/. Accessed 20 Feb 2021.

UIS. (2020). Egypt education and literacy profile. Available via UNESCO Institute for Statistics. http://uis.unesco.org/en/country/eg?theme=education-and-literacy. Accessed 13 Nov 2020.

UNICEF. (2017). Children in Egypt: aged 0-17, census 2017. Available via United Nations Children's Fund. https://www.unicef.org/egypt/media/5341/file/Children\%20(English). pdf. Accessed 7 Nov 2020.

UNICEF MENA. (2017). Reimagining life skills and citizenship education in the Middle East and North Africa. Available via United Nations Children's Fund. https://www.unicef.org/mena/rep orts/reimagining-life-skills-and-citizenship-education-middle-east-and-north-africa. Accessed 17 Oct 2020.

UNICEF. (2018). A new learning agenda for the realization of SDG 4 in MENA. Available via United Nations Children's Fund. https://www.unicef.org/mena/media/6231/file/Operationalizat ion\%20of\%20LSCE\%20in\%20Jordan.pdf\%20.pdf. Accessed 19 Oct 2020.

UNICEF. (2019). Key achievements in the education reform. Available via United Nations Children's Fund. https://www.unicef.org/egypt/press-releases/key-achievements-educational-reform. Accessed 30 Oct 2020.

UNICEF. (2020). Education in Egypt. Available via United Nations Children's Fund. https://www. unicef.org/egypt/education. Accessed 3 Nov 2020.

United Nations. (2020). World Population Prospects-Population Division-United Nations. Retrieved January 6, 2022, from https://population.un.org/wpp/Graphs/Probabilistic/POP/ TOT/818.

USAID. (2020a). Egypt basic education. Available via United States Agency for International Development. https://www.usaid.gov/egypt/basic-education. Accessed 5 Dec 2020.

USAID. (2020b). Teach for tomorrow. Available via United States Agency for International Development. https://www.usaid.gov/egypt/basic-education/teach-tomorrow. Accessed $10 \mathrm{Dec}$ 2020.

USAID. (2020c). Early grade learning. Available via United States Agency for International Development. https://www.usaid.gov/egypt/basic-education/early-grade-learning. Accessed 4 Nov 2020.

Walsh, D. (2020). As Egypt's population hits 100 million, celebration is muted. Available via The New York Times. https://www.nytimes.com/2020/02/11/world/middleeast/egypt-popula tion-100-million.html. Accessed 16 Sept 2020.

World Bank. (2018). Supporting Egypt education reform project. Available via World Bank. http://documents1.worldbank.org/curated/en/346091522415590465/pdf/PAD-03272018. pdf. Accessed 8 Sept 2020.

World Bank. (2019). Improving teaching and learning conditions in Egypt's public schools. Available via World Bank. https://www.worldbank.org/en/news/infographic/2019/08/06/improvingteaching-and-learning-conditions-in-egypts-public-schools. Accessed 22 Aug 2020.

World Bank. (2020). Egypt Arab rep data. Available via World Bank. https://data.worldbank.org/ country/egypt-arab-rep. Accessed 22 Aug 2020.

World Bank Education Statistics. (2021a). Education expenditures. Available via World Bank Education Statistics. https://datatopics.worldbank.org/education/wDashboard/dqexpenditures. Accessed 11 Sept 2020.

World Bank Education Statistics (2021b) Country at a glance - Egypt, Arab Rep. Available via World Bank Education Statistics. https://data.worldbank.org/country/EG. Accessed 15 Sept 2020.

Zaki Ewiss, A., Abdelgawad, F., \& Elgendy, A. (2019). School educational policy in Egypt: Societal assessment perspective. Journal of Humanities and Applied Social Sciences, 1, 55-68. https:// doi.org/10.1108/JHASS-05-2019-004 
Nariman Moustafa is an international education consultant with a decade of experience. Based in Cairo, Egypt, she is the founder and director of Mesahat: Liberating Learning Spaces, a collective of self-organized community learning spaces spreading tools, values and principles of selflearning, democratic and justice-based education, envisioning the creation of lifelong learning cities. In addition to being a steering member of the Ecoversities Alliance, a global collective of learning experiences reimagining the future of higher education. Nariman obtained her Ed.M. degree from the Harvard Graduate School of Education. Her research work is concerned with cognitive justice and decolonial education.

Ebtehal Elghamrawy has a decade of experience in international development and education reform. Until recently she was the programs manager and management committee member of "Educate Me" (EM) foundation. There she launched and led the programs department. Prior to that she worked as an implementer, project manager, and M\&E consultant at UNICEF, Grameen Creative Lab (Germany), Yunus Centre (Bangladesh), FHI360 INGO, TEDxCairo, and AIESEC (Egypt, China). She has two master's degrees- a joint European MA in Comparative Local Development, and an Ed.M in International Education Policy from Harvard Graduate School of Education. Her work and research focus on how to scale quality primary education interventions in low-income contexts.

Katherine King holds a master's degree in International Higher Education from Lesley University in Cambridge, MA and is currently working towards an Ed.D in higher education administration at Northeastern University. She is employed as an Education Program Manager at Harvard Medical School, working with students who are seeking advanced training in clinical service operations. Katherine has worked in international student services for five years, both with US citizens studying abroad and with international students coming to the United States. Her interests include internationalization of the higher education curriculum, international student services, and social change via international exchange.

Yu (Claire) Hao is the Director of Education at Beijing Xinxuedao Education Group, a nonprofit organization that currently operates $25 \mathrm{~K}-12$ schools across China. Claire has five years of experience managing schools in China, and her works focus on supporting bilingual students and teachers through curriculum development and professional development. Claire earned her B.A. in Education and Physics from University of Cambridge, M.A. in Applied Linguistics from UCL Institute of Education, and Ed.M. in International Education Policy from Harvard Graduate School of Education.

Open Access This chapter is licensed under the terms of the Creative Commons Attribution 4.0 International License (http://creativecommons.org/licenses/by/4.0/), which permits use, sharing, adaptation, distribution and reproduction in any medium or format, as long as you give appropriate credit to the original author(s) and the source, provide a link to the Creative Commons license and indicate if changes were made.

The images or other third party material in this chapter are included in the chapter's Creative Commons license, unless indicated otherwise in a credit line to the material. If material is not included in the chapter's Creative Commons license and your intended use is not permitted by statutory regulation or exceeds the permitted use, you will need to obtain permission directly from the copyright holder.

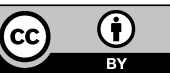

